\title{
Accumulation of Plasma Triiodothyronine Sulfate in Rats Treated with Propylthiouracil
}

\author{
Marja Rutgers, Fred Bonthuis, Wouter W. de Herder, and Theo J. Visser \\ Departments of Internal Medicine I and III, Erasmus University Medical School, Rotterdam, The Netherlands
}

\begin{abstract}
Triiodothyronine sulfate $\left(\mathrm{T}_{3} \mathrm{~S}\right)$ is rapidly deiodinated by the propylthiouracil (PTU)-sensitive type I deiodinase. Here we examined the effects of PTU on plasma $T_{3} S$ levels in rats after intravenous administration of radiolabeled $T_{3}$ or $T_{3} S$. Sephadex LH-20 chromatography and high-performance liquid chromatography were used to quantify conjugated and nonconjugated iodothyronines, and iodide was measured as the TCAsoluble radioactivity. In control rats, radioiodide was the main metabolite of both $T_{3}$ and $T_{3} S$. Plasma $T_{3} S$ was cleared more rapidly than plasma $T_{3}$ despite increased binding to plasma proteins. PTU reduced plasma iodide levels by 66 and $78 \%$ after $T_{3}$ and $T_{3} S$, respectively, and decreased plasma clearance of $T_{3} S$ by $81 \%$. However, PTU had no effect on plasma $T_{3}$ clearance but increased plasma $T_{3} S$ from injected $T_{3} 4.2$ times. Biliary excretion of injected $\mathrm{T}_{3} \mathrm{~S}$ was $<20 \%$ in normal rats, in contrast to $70 \%$ within $4 \mathrm{~h}$ in PTU-treated rats. In conclusion, $\mathrm{T}_{3} \mathrm{~S}$ is an important intermediate in the in vivo metabolism of $T_{3}$ in rats and accumulates in plasma if type $I$ deiodination is inhibited.
\end{abstract}

\section{Introduction}

Stepwise monodeiodination plays a central role in the metabolism of thyroid hormone in peripheral organs such as liver and kidney $(1,2)$. After the bioactivation of thyroxine $\left(T_{4}\right)^{1}$ to 3,3',5-triiodothyronine $\left(T_{3}\right)$ by outer ring deiodination, $T_{3}$ is further converted to biologically inactive iodothyronines by successive deiodination in inner and outer rings (3). In humans, metabolic pathways other than deiodination seem equally important for the inactivation and elimination of $\mathrm{T}_{3}$ (1). Conjugates of $T_{3}$ with glucuronic acid or sulfate have been detected by Bollman and Flock (4) in bile and urine of rats and dogs.

In vitro, enzyme kinetic studies with liver type I deiodinase have shown that, in contrast to $T_{3}$ itself, $T_{3}$ sulfate $\left(T_{3} S\right)$ is

Reported in abstract form in the Program of the 61 st Annual Meeting of the American Thyroid Association, Phoenix AZ, 1986. (Abstr. 74.)

Address correspondence to Theo J. Visser, Ph.D., Department of Internal Medicine III, Erasmus University Medical School, P.O. Box 1738, 3000 DR Rotterdam, The Netherlands.

Received for publication 27 February 1987.

1. Abbreviations used in this paper: BW, body weight; G, glucuronide; HPLC, high-performance liquid chromatography; PTU, 6-propyl-2thiouracil; S, sulfate; SPE, solid-phase extraction; $T_{2}, 3,3^{\prime}$-diiodothyronine; $T_{3}, 3,3$, 5-triiodothyronine; $T_{4}$, thyroxine.

J. Clin. Invest.

(C) The American Society for Clinical Investigation, Inc. 0021-9738/87/09/0758/05 \$2.00

Volume 80, September 1987, 758-762 rapidly deiodinated in the inner ring (5). The 3,3'-diiodothyronine sulfate $\left(\mathrm{T}_{2} \mathrm{~S}\right)$ produced is also a much better substrate for outer ring deiodination than nonconjugated $T_{2}(5,6)$. Under normal conditions primary cultures of rat hepatocytes metabolize added $\left[{ }^{125} \mathrm{I}\right] \mathrm{T}_{3}$ to iodide and $\mathrm{T}_{3}$ glucuronide $\left(\mathrm{T}_{3} G\right)$. Addition of the type I deiodinase inhibitor 6-propyl-2-thiouracil (PTU) results in accumulation of the $T_{3} S$ intermediate without affecting $T_{3}$ clearance (6). Iodide production is also decresed in sulfate-deplete cells or by inhibitors of phenol sulfotransferase, but under these conditions $T_{3}$ clearance is diminished as well (6). It was subsequently shown that PTU treatment resulted in a fivefold increase in biliary $\mathrm{T}_{3} S$ after administration of $\left[{ }^{125} \mathrm{I}\right] \mathrm{T}_{3}$ to rats without affecting excretion of $\mathrm{T}_{3} \mathrm{G}^{2}$ (7). Therefore, sulfation and subsequent deiodination is an important metabolic pathway for $T_{3}$ in rat liver. To further investigate the physiological relevance of this pathway we analyzed plasma $T_{3} S$ in rats with impaired type I deiodinase activity.

\section{Methods}

Materials. [ $\left.{ }^{125} \mathrm{I}\right] \mathrm{T}_{3}$ was synthesized by radioiodination of 3,5-diiodothyronine (Henning GmbH, Berlin, FRG) with carrier-free $\mathrm{Na}^{125}$ I (Amersham Corp., Amersham, UK) using the chloramine T method. The sulfate conjugate of $\left.{ }^{125} I\right] \mathrm{T}_{3}$ was prepared with chlorosulfonic acid in dimethylformamide and purified on Sephadex LH-20 (8). PTU was purchased from Sigma Chemical Co., St Louis, MO. All other chemicals were of analytical grade.

Experimental procedures. Male Wistar rats, $230-350 \mathrm{~g}$ body weight (BW), were anesthetized by injection of $5 \mathrm{mg}$ i.p. pentobarbital sodium per $100 \mathrm{~g} \mathrm{BW}$. Additional injections of 2-5 mg pentobarbital were administered during the experiment if necessary. Body temperature was maintained by placing the animals under an infrared lamp. A $100-\mathrm{mM}$ PTU solution in $0.1 \mathrm{M} \mathrm{NaOH}$ was diluted five times in phosphate-buffered saline. Rats were injected with $220 \mu$ li.v. $(0.75 \mathrm{mg}$ PTU) per $100 \mathrm{~g} \mathrm{BW}$ of this mixture. Controls were studied in parallel and received the same volume of vehicle. 30 min later $\sim 10 \mu \mathrm{Ci}$ $\left[{ }^{125} \mathrm{I}_{\mathrm{T}} \mathrm{T}_{3}\right.$ or ${ }^{125} \mathrm{I}^{12} \mathrm{~T}_{3} \mathrm{~S}$ in $500 \mu \mathrm{l} 0.01 \mathrm{M} \mathrm{NaOH}$ in saline was injected intravenously $(t=0)$. Blood samples $(0.75 \mathrm{ml})$ were taken from the tail vein at $0.5,1$, and $2 \mathrm{~h}$, and after cervical dislocation at $4 \mathrm{~h}$ the animals were bled by heart puncture.

Biliary excretion of intravenously injected $\left[{ }^{125} \mathrm{I}\right] \mathrm{T}_{3} \mathrm{~S}$ was studied as follows. The biliary duct of pentobarbital-anesthetized rats (200 g BW) was cannulated ${ }^{2}$ and the animals were injected with PTU or vehicle followed by $10 \mu \mathrm{Ci}\left[{ }^{125}{ }^{1}\right] \mathrm{T}_{3} \mathrm{~S}$ as described above. Blood samples $(0.3$ $\mathrm{ml}$ ) were obtained in heparinized vials after $0.5,1,2$, and $4 \mathrm{~h}$, and bile was collected in 10-20 min periods.

In a parallel experiment PTU was administered $2 \mathrm{~h}$ before the animals were anesthetized whereupon the bile duct was cannulated and [ $\left.{ }^{125} \mathrm{I}\right] \mathrm{T}_{3}$ injected, i.e., $2.5 \mathrm{~h}$ after PTU. Bile and plasma were collected until $4 \mathrm{~h}$ after $T_{3}$ injection.

2. De Herder, W. W., F. Bonthuis, M. Rutgers, M. H. Otten, M. P. Hazenberg, and T. J. Visser. Effects of inhibition of type I iodothyronine deiodinase and phenol sulfotransferase on the biliary clearance of triiodothyronine in rats. Submitted for publication. 
Analysis of samples. Serum and bile were kept at $-20^{\circ} \mathrm{C}$ until further analysis. Plasma ${ }^{125} \mathbf{I}^{-}$was measured as trichloroacetic acid (TCA)-soluble radioactivity. For this purpose, 50-100 $\mu \mathrm{l}$ serum was mixed with $10 \%(\mathrm{wt} / \mathrm{vol})$ ice-cold TCA to a final volume of $500 \mu \mathrm{l}$. After 10 min at $0^{\circ} \mathrm{C}$, mixtures were centrifuged and radioactivity was determined in the supernatant. Radioiodide in bile was estimated similarly by addition of $100 \mu \mathrm{l}$ pooled human serum to 10-25 $\mu \mathrm{l}$ bile followed by $400 \mu \mathrm{l} 10 \%$ TCA. $>95 \%$ of $\mathrm{T}_{3}$ or $\mathrm{T}_{3} \mathrm{~S}$ added to plasma or bile was precipitated by TCA while on average $97 \%$ of added ${ }^{125} \mathrm{I}^{-}$ remained in solution.

For analysis of other plasma metabolites, mixtures were prepared consisting of $250 \mu \mathrm{l}$ serum, $500 \mu \mathrm{l} 0.2 \mathrm{M} \mathrm{HCl}$, and $250 \mu \mathrm{l}$ ethanol. These were applied to small Sephadex LH-20 columns (bed vol, 1.3 $\mathrm{ml}$ ) equilibrated in $0.1 \mathrm{M} \mathrm{HCl}$. After rinsing the columns with $0.1 \mathrm{M}$ $\mathrm{HCl}$, conjugated and nonconjugated iodothyronines were eluted successively with $20 \%$ ethanol in water and $0.1 \mathrm{M}$ ammonia in ethanol. Fractions of $1 \mathrm{ml}$ were collected and counted for radioactivity. Recovery of $T_{3} S$ and $T_{3}$ added to rat plasma amounted to 91 and 94\%, respectively. For further identification of the isolated products by high-performance liquid chromatography (HPLC), peak fractions of corresponding time points were combined within each experimental group. The conjugate pool was lyophylized and the iodothyronine pool was evaporated under a stream of nitrogen at $50^{\circ} \mathrm{C}$.

Iodothyronines and their conjugates were isolated from the 4-h plasma samples by solid-phase extraction (SPE) for subsequent analysis by HPLC. In short, $500 \mu l$ serum was mixed with an equal volume $0.25 \mathrm{M} \mathrm{NaOH}$ and applied to a $\mathrm{C}_{18}$-SPE column (500 mg, J. T. Baker Chemical Co., Phillipsburg, NJ). Columns were washed successively with $2 \times 1 \mathrm{ml}$ of each $0.1 \mathrm{M} \mathrm{NaOH}, \mathrm{H}_{2} \mathrm{O}, 0.1 \mathrm{M} \mathrm{HCl}$, and $\mathrm{H}_{2} \mathrm{O}$ before elution of both conjugates and iodothyronines with $1 \mathrm{ml}$ methanol. The recovery of $T_{3}$ and $T_{3} S$ added to rat plasma was 90 and $96 \%$, respectively.

HPLC analysis. Reversed-phase HPLC was done on a $10 \times 0.3-\mathrm{cm}$ Chromspher $\mathrm{C}_{18}$ analytical column in combination with a $10 \times 2.1-$ mm guard column (Chrompack International BV, Middelburg, Netherlands). Elution was performed with a 20 -min gradient of $18-40 \%$ acetonitrile in $0.02 \mathrm{M}$ ammonium acetate (pH 4). Solvent flow was 0.8 $\mathrm{ml} / \mathrm{min}$ and fractions of $0.5 \mathrm{~min}$ were collected. A nonlinear gradient (No. 7) as programmed by the automated gradient controller (model 680, Waters Associates, Milford, MA) was used. The residues of the plasma extracts were dissolved in mobile phase and the gradient was started at the time of injection. Retention times of possible products were determined using synthetic and biosynthetic reference compounds (9). HPLC analysis of biliary products was performed on 5-25- $\mu$ l aliquots of bile diluted with 4 vol of mobile phase. Analysis, especially of glucuronide conjugates in bile, was more accurate if a 25 -min gradient of $16-40 \%$ acetonitrile was used.

\section{Results}

Identification of metabolites. All metabolites of interest were well separated using reversed-phase HPLC, and a typical chromatogram is shown in Fig. 1. Neither serum residues nor small amounts of bile in the HPLC samples affected the elution profile seen with pure tracers.

Analysis of plasma $T_{3}$ and $T_{3} S$ metabolites. Fig. 2 shows the distribution of the major radioactive compounds in plasma $2 \mathrm{~h}$ after administration of the tracers as determined by LH-20 chromatography. Further analysis of the obtained conjugate and iodothyronine fractions by reversed-phase HPLC is illustrated in Fig. 3. HPLC of the LH-20 fractions of plasma obtained after $0.5,1$, and $4 \mathrm{~h}$ indicated similar compositions. On average, $78 \%$ of the radioactivity in the conjugate fraction coeluted with $\mathrm{T}_{3} \mathrm{~S}$ on HPLC, while $84 \%$ of the iodothyronine fraction eluted as $T_{3}$. If plasma was spiked with labeled $T_{3}$ or $\mathrm{T}_{3} \mathrm{~S}$, in both cases $89 \%$ of the radioactivity in the respective

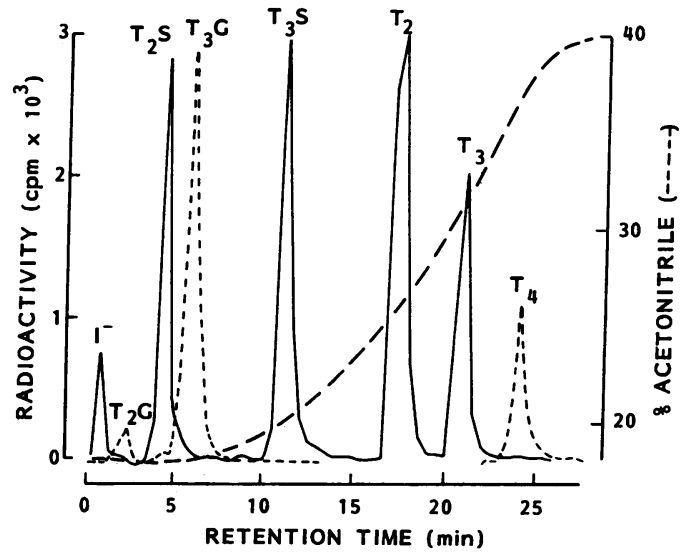

Figure 1. Separation by reversed-phase HPLC of a mixture of ${ }^{125}$ I-labeled sulfates $(S)$, glucuronides $(G)$, and nonconjugated iodothyronines. The $\mathrm{C}_{18}$ column was eluted at $0.8 \mathrm{ml} / \mathrm{min}$ using a 20 -min gradient of $18-40 \%$ acetonitrile in $0.02 \mathrm{M}$ ammonium acetate (pH 4). (Dashed curve) Actual composition of the mobile phase.

LH-20 fractions eluted as $T_{3}$ or $T_{3} S$ on HPLC. Therefore, plasma radioactivity other than iodide as fractionated on LH-20 consisted predominantly of $\mathrm{T}_{3} \mathrm{~S}$ or $\mathrm{T}_{3}$. Nonconjugated $T_{2}$ was never observed, but $T_{2} S$ was detected in $T_{3}$-injected rats where it comprised on average $10 \%$ of the radioactivity in the

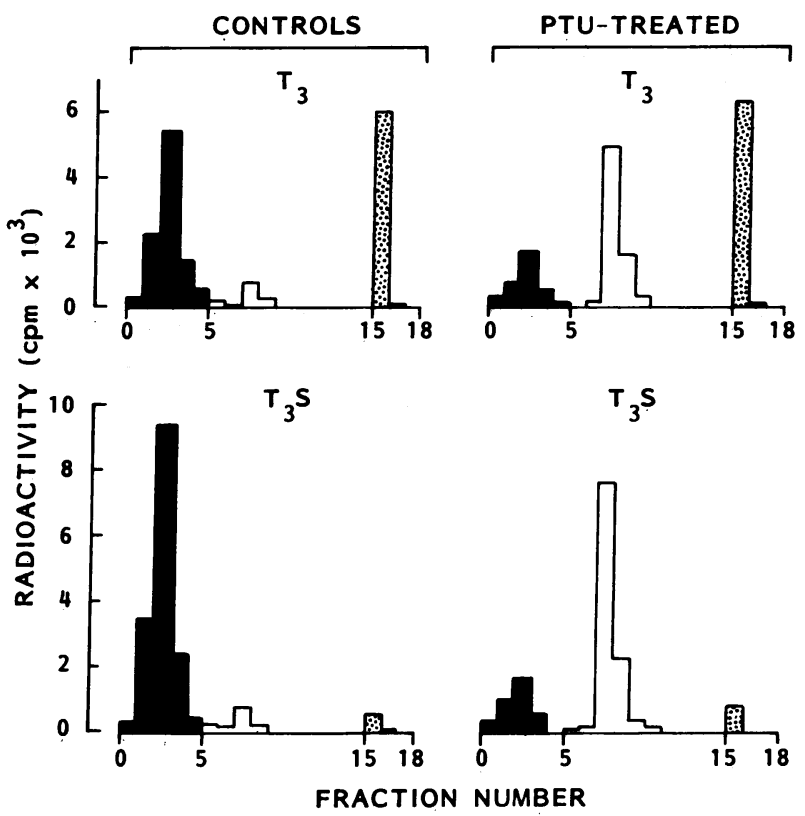

Figure 2. Sephadex LH-20 chromatography of serum from rats injected with $\mathrm{T}_{3}$ or $\mathrm{T}_{3} \mathrm{~S}$. Rats received saline (left) or PTU (right) 30 min prior to $10 \mu \mathrm{Ci}\left[{ }^{125} \mathrm{I}\right] \mathrm{T}_{3}$ (upper) or $\left[{ }^{125} \mathrm{I}\right] \mathrm{T}_{3} \mathrm{~S}$ (lower) by intravenous injections. Serum $(0.25 \mathrm{ml})$ was acidified and applied to Sephadex LH-20 columns as described in Methods. Free iodide, conjugated and nonconjugated iodothyronines were successively eluted with $0.1 \mathrm{M} \mathrm{HCl}$ (fractions 1-5), 20\% ethanol in water (fractions 6-14), and $0.1 \mathrm{M}$ ammonia in ethanol (fractions $16-18$ ) with a recovery of $95 \%$ for $\mathrm{I}^{-}, 91 \%$ for $\mathrm{T}_{3} \mathrm{~S}$, and $94 \%$ for $\mathrm{T}_{3}$. Mean values for each experimental group are given $\left(T_{3}, n=5 ; T_{3} S, n=4\right)$. Total radioactivity in the samples amounted to $0.39\left(\mathrm{~T}_{3}\right), 0.34\left(\mathrm{~T}_{3}+\mathrm{PTU}\right)$, $0.42\left(\mathrm{~T}_{3} \mathrm{~S}\right)$, and $0.31\left(\mathrm{~T}_{3} \mathrm{~S}+\mathrm{PTU}\right) \%$ dose $/ \mathrm{ml}$ plasma. 


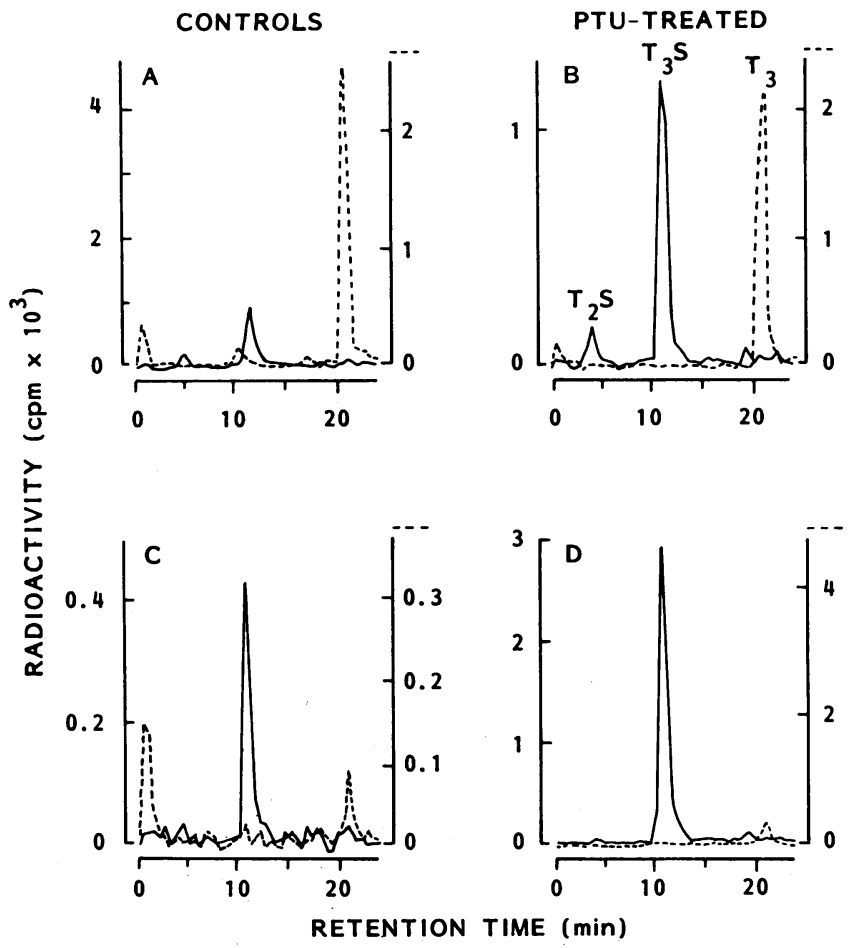

Figure 3. HPLC analysis of serum $\mathrm{T}_{3}$ and $\mathrm{T}_{3} \mathrm{~S}$ fractions. Serum was obtained from control and PTU-treated rats $2 \mathrm{~h}$ after injection of $\left[{ }^{125} \mathrm{I}\right] \mathrm{T}_{3}(A$ and $B)$ or $\left[{ }^{125} \mathrm{I}\right] \mathrm{T}_{3} \mathrm{~S}(C$ and $D)$ and chromatographed on Sephadex LH-20 (Fig. 2). Corresponding conjugate (solid line) or iodothyronine (dashed line) fractions were pooled for each experimental group and further analyzed by HPLC (Fig. 1). Chromatograms represent $\sim 49,80,25$, and $78 \%$ of total plasma radioactivity due to removal of mainly ${ }^{125} \mathrm{I}^{-}$by $\mathrm{LH}-20$ from samples $A, B, C$, and $D$, respectively. Note the smaller scale in $C$, where the first peak represents only $2 \%$ of plasma iodide.

conjugate fraction. After $T_{3} S$ injection, plasma $T_{3}$ was negligible in control rats and represented $<4 \%$ of plasma radioactivity in PTU-treated rats. Neither $T_{4}$ nor the glucuronides of $T_{3}$ and $T_{2}$ were observed in any of the samples. HPLC of solidphase extracts of 4-h plasma samples were in close agreement with analysis of the LH-20 fractions.

$>95 \%$ of radioiodide added to plasma eluted in the first five fractions of the LH-20 chromatography. However, coelution of some protein-bound radioactivity or unknown metabolites could not be excluded. Therefore, accurate measurements of free iodide in plasma was performed by TCA precipitation. The radioactivity in the $\mathrm{HCl}$ fractions after $\mathrm{LH}-20$ correlated well with the amount of TCA-soluble radioactivity as shown by linear regression analysis. For the means of these parameters in the different experimental groups the following function was derived: $y(\mathrm{HCl})=1.3 x(\mathrm{TCA})+0.1(r=0.997, n$ $=16$ ) with $x$ and $y$ expressed as percentage of plasma radioactivity. Apparently, the LH-20 method overestimated plasma iodide levels and was not used for calculation of the results.

Effect of PTU on the metabolism of $T_{3}$ and $T_{3} S$. Results of the measurement of plasma $T_{3}$ and $T_{3} S$ by Sephadex LH-20 and of iodide by TCA precipitation are summarized in Fig. 4. Radioiodide was the main plasma metabolite of both $T_{3}$ and $\mathrm{T}_{3} \mathrm{~S}$ in control rats. PTU did not affect plasma $T_{3}$ clearance but decreased $T_{3} S$ clearance by $81 \%$, as estimated from the area

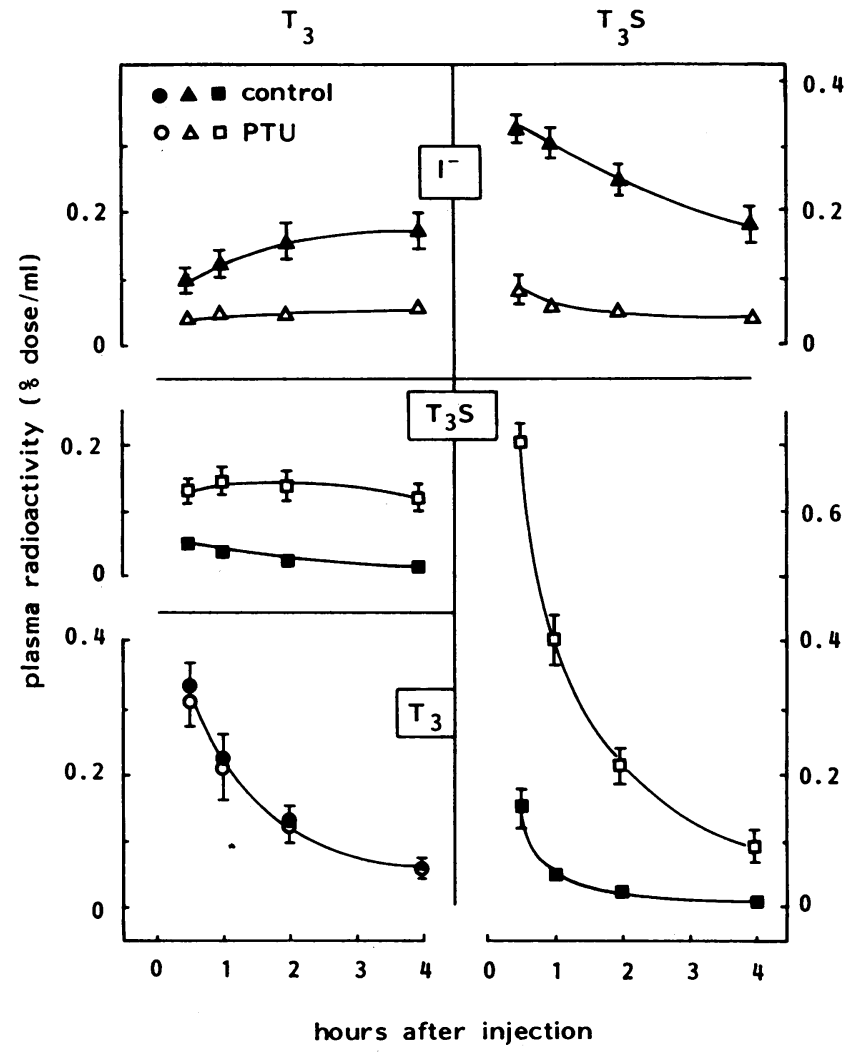

Figure 4. Effect of PTU on plasma $T_{3}$ and $T_{3} S$ metabolites. Serum was analyzed from rats injected with $\left[{ }^{125} \mathrm{I}\right] \mathrm{T}_{3}(l e f t)$ or $\left[{ }^{125} \mathrm{I}\right] \mathrm{T}_{3} \mathrm{~S}($ right $)$ after pretreatment with saline (solid symbols) or PTU (open symbols). Plasma iodide (triangles) was estimated as the TCA-soluble radioactivity, whereas $\mathrm{T}_{3} \mathrm{~S}$ (squares) and $\mathrm{T}_{3}$ (circles) were quantified by Sephadex LH-20 fractionation (Fig. 2). In [ $\left.{ }^{125} \mathrm{I}\right] \mathrm{T}_{3}$-injected rats roughly $10 \%$ of the radioactivity in the " $T_{3} S$ fraction" consisted of $\mathrm{T}_{2} \mathrm{~S}$. Radioactivity of compounds is expressed as mean percent dose per milliliter plasma ( \pm SD unless smaller than symbol) and plotted as a function of time after tracer injection. Total amount of plasma radioactivity decreased over the 4-h period from $0.52 \pm 0.07$ to $0.33 \pm 0.05$ after $\mathrm{T}_{3}(n=5)$, from $0.50 \pm 0.08$ to $0.26 \pm 0.04$ after $\mathrm{T}_{3}$ + PTU $(n=5)$, from $0.68 \pm 0.04$ to $0.29 \pm 0.04$ after $\mathrm{T}_{3} \mathrm{~S}(n=4)$, and from $0.82 \pm 0.03$ to $0.17 \pm 0.03$ after $\mathrm{T}_{3} \mathrm{~S}+\mathrm{PTU}(n=4)$. Except for plasma disappearance of $T_{3}$, differences between controls and PTU rats were highly significant $(P<0.001)$ as estimated by Student's unpaired $t$ test.

under the plasma $T_{3} S$ concentration curve. In control rats clearance of plasma $T_{3} S$ was faster than that of $T_{3}$, but the reverse was true after PTU treatment. The administration of PTU diminished plasma iodide levels by $60-71 \%$ after $T_{3}$ injection and by $74-80 \%$ after $T_{3} S$. PTU increased plasma $T_{3} S$ 2.7 times at $0.5 \mathrm{~h}$ to 7.5 times at $4 \mathrm{~h}$ after $\mathrm{T}_{3}$ injection, with an average of 4.2 times. This resulted in $\mathrm{T}_{3} \mathrm{~S}$ being the major radioactive compound in plasma from $2 \mathrm{~h}$ after $\mathrm{T}_{3}$ injection onwards. Similar results were obtained in rats with bile cannules, where $T_{3}$ injection was delayed until $2.5 \mathrm{~h}$ as opposed to $0.5 \mathrm{~h}$ after PTU administration.

Biliary clearance of $T_{3} S$ (Fig. 5). In control rats $<20 \%$ of radioactivity injected as $T_{3} S$ was excreted in the bile, occurring predominantly during the first $30 \mathrm{~min}$. In PTU-treated rats biliary excretion was greatly increased up to $70 \%$ of the dose after $4 \mathrm{~h}$. HPLC analysis demonstrated that $\mathrm{T}_{3} \mathrm{~S}$ was the only 


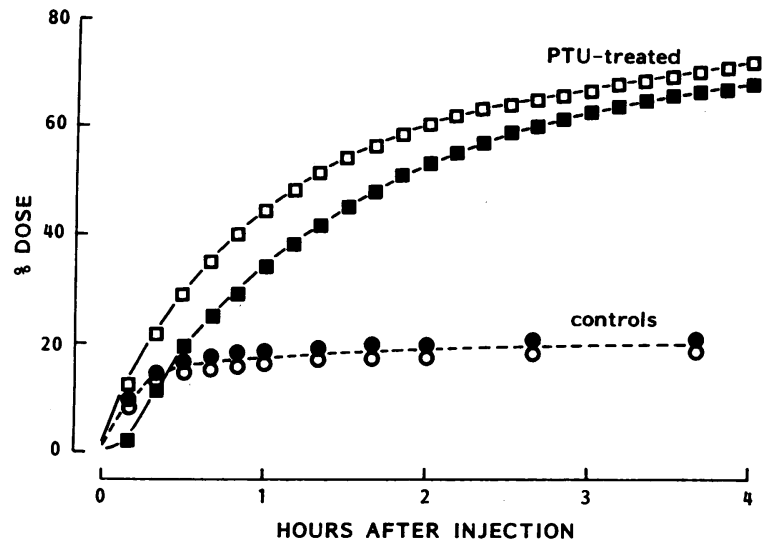

Figure 5. Biliary clearance of $\mathrm{T}_{3} \mathrm{~S}$. Rats with bile cannules under pentobarbital anesthesia received intravenous injections of PTU or saline $30 \mathrm{~min}$ before $10 \mu \mathrm{Ci}\left[{ }^{125} \mathrm{I}\right] \mathrm{T}_{3} \mathrm{~S}$. Cumulative excretion was estimated by summation of radioactivity in successive 10 -min bile aliquots and expressed as percent dose. Different symbols represent individual rats. Total bile volumes collected over $4 \mathrm{~h}$ were 3.5 (open circle), 4.4 (solid circle), 3.7 (open square), and 4.2 (solid square) $\mathrm{ml}$. Bile flow was low in one of the PTU-treated rats (solid square) during the first $10 \mathrm{~min}$.

significant compound in bile. Iodide was excreted only in bile of control rats and amounted to $2.5 \%$ of the administered dose. $\mathrm{T}_{2} \mathrm{~S}$ was observed in bile of PTU-treated rats but accounted for $<3 \%$ of the biliary radioactivity. In these cannulated rats distribution of plasma radioactivity was the same as in intact rats and pretreatment with PTU resulted in a $57-84 \%$ decrease in plasma iodide over the 4-h period.

Plasma free $T_{3}$ and $T_{3} S$ fractions. The non-protein-bound fractions of $T_{3}$ and $T_{3} S$ in rat plasma were determined in duplicate by equilibrium dialysis. The free fraction was $0.35 \pm 0.03($ mean $\pm S D, n=6)$ for $\mathrm{T}_{3}$ and $0.20 \pm 0.03(n=4)$ for $\mathrm{T}_{3} \mathrm{~S}$, and both were unaffected by $1 \mathrm{mM}$ PTU.

\section{Discussion}

The role of conjugation in the metabolism of thyroid hormone, especially in humans, has received little attention in the literature. Extensive conjugation of thyroid hormone has been demonstrated in experimental animals. Bollman and Flock (4) have identified glucuronides as the main excretory products of various iodothyronines in the bile of normal rats. However, the sum of $T_{2} S$ and $T_{3} S$ excreted in bile equalled or exceeded that of $T_{3} G$ after administration of $T_{3}$ to dogs $(10,11)$. Studying the biliary clearance of $T_{4}$ in rats, Flock and Bollman (12) observed that thiouracil treatment increased the excretion of an acid-hydrolyzable $T_{4}$ conjugate which perhaps represented $\mathrm{T}_{4}$ sulfate (8). A similar effect was also observed with butyl 4-hydroxy-3,5-diiodobenzoate, which is also an inhibitor of type I deiodinase activity. Treatment of rats with this compound in addition to labeled $T_{3}$ or $T_{4}$ led to a far greater increase in biliary sulfates compared with glucuronides (13).

Roche et al. (14) reported on the presence of radioactive $\mathrm{T}_{3} \mathrm{~S}$ in bile and plasma of thyroidectomized rats after injection with labeled $T_{3}$. We previously observed an increase in biliary $T_{3} S$ from exogenous $T_{3}$ in rats treated with PTU $^{2}(7)$. We have now shown that the same treatment results in a marked accu- mulation of plasma $T_{3} S$. In retrospect, it is possible to explain the findings of Roche et al. (14) as it has become evident that hypothyroidism in rats is associated with an impaired hepatic deiodinase activity (15). Although these investigators did not study euthyroid rats, their results agree with ours, indicating that $\mathrm{T}_{3} \mathrm{~S}$ accumulates if subsequent deiodination is inhibited.

In control rats, injected $T_{3} S$ is metabolized more rapidly than $T_{3}$ although it binds with higher affinity to plasma proteins, and only radioiodide was detected as a metabolite. Similar rapid deiodinative clearance of $T_{3} S$ in humans has been reported recently (16). Clearance of $T_{3} S$ is strongly inhibited by PTU, indicating that it is largely metabolized by type I deiodination. In contrast, $T_{3}$ disposition is not affected by PTU as also observed by others (17), illustrating that direct inner ring deiodination of $T_{3}$ by the liver type I deiodinase is a negligible metabolic pathway. The slower metabolic clearance rate of $T_{3} S$ compared with $T_{3}$ in PTU-treated rats has also been observed in thyroidectomized rats (18) and entirely explains the increase in plasma $T_{3} S$ from exogenous $T_{3}$. The plasma $\mathrm{T}_{3} \mathrm{~S}$ levels thus obtained underscore the importance of sulfation as metabolic pathway of $T_{3}$.

In PTU-treated rats plasma $T_{3} S$ is cleared predominantly by biliary excretion. It is possible, therefore, that also after injection of $T_{3}$ most $T_{3} S$ in bile is derived from plasma $T_{3} S$. Although $\mathrm{T}_{3}$ is sulfated and glucuronidated in rat hepatocytes (6), it is not excluded that part of plasma $T_{3} S$ originates by sulfation of $T_{3}$ in other tissues as was observed in hepatectomized dogs $(4,10)$.

Plasma $\mathrm{T}_{2} \mathrm{~S}$ was observed in both normal and PTU-treated rats after injection of $T_{3}$ but not after $T_{3} S$. Therefore, it is probably derived from sulfation of $T_{2}$ that is produced by PTU-insensitive (type III) inner ring deiodination of $T_{3}(2)$. This would also explain the marked biliary $\mathrm{T}_{2} \mathrm{~S}$ excretion after $\mathrm{T}_{3}$ injection to PTU-treated rats ${ }^{2}(7)$ in contrast to the negligible amounts of $\mathrm{T}_{2} \mathrm{~S}$ in bile of $\mathrm{T}_{3} \mathrm{~S}$-injected rats (this study).

In conclusion, the present study of plasma $T_{3} S$ formation in $T_{3}$-injected rats extends previous observations in bile, indicating that sulfation is an important pathway of $T_{3}$ metabolism in rats. However, unless subsequent type I deiodination of the conjugate is prevented, little $T_{3} S$ is observed in both body fluids. The finding of significant amounts of $T_{3} S$ in rat plasma opens the perspectives of studying the importance of $T_{3}$ sulfation in humans. The recent development of a radioimmunoassay for $\mathrm{T}_{3} \mathrm{~S}$ in our laboratory should facilitate such investigations (19). The findings that in human liver $T_{3}$ is a substrate for phenol sulfotransferase (20) and that $T_{3} S$ is rapidly deiodinated (21) suggest that successive sulfation and deiodination of $T_{3}$ indeed occurs in humans.

\section{Acknowledgments}

We thank Hans van Toor and Frank Heusdens for experimental assistance.

These investigations were supported in part by the Foundation for Medical Research MEDIGON (grant 900-540-191).

\section{References}

1. Engler, D., and A. G. Burger. 1984. The deiodination of the iodothyronines and their derivatives in man. Endocr. Rev. 5:151-184.

2. Leonard, J. L., and T. J. Visser. 1986. Biochemistry of deiodina- 
tion. In Thyroid Hormone Metabolism. G. Hennemann, editor. Marcel Dekker, New York. 189-229.

3. Visser, T. J., D. Fekkes, M. H. Otten, J. A. Mol, R. Docter, and G. Hennemann. 1984. Deiodination and conjugation of thyroid hormone in rat liver. In Hormones and Cell Regulation. Vol. 8. J. E. Dumont and J. Nunez, editors. Elsevier/North-Holland, Amsterdam. 179-191.

4. Bollman, J. L., and E. V. Flock. 1965. The role of the liver in the metabolism of $\mathrm{I}^{131}$-thyroid hormones and analogues. In The Biliary System. W. Taylor, editor. Blackwell, Oxford. 345-365.

5. Visser, T. J., J. A. Mol, and M. H. Otten. 1983. Rapid deiodination of triiodothyronine sulfate by rat liver microsomal fraction. Endocrinology. 112:1547-1549.

6. Otten, M. H., J. A. Mol, and T. J. Visser. 1983. Sulfation preceeding deiodination of iodothyronines in rat hepatocytes. Science (Wash. DC). 221:81-83.

7. De Herder, W. W., F. Bonthuis, M. P. Hazenberg, and T. J. Visser. 1986. Biliary excretion and reabsorption of $\mathrm{T}_{3}$ and its metabolites. Ann. Endocrinol. 47:23. (Abstr.)

8. Mol, J. A., and T. J. Visser. 1985. Synthesis and some properties of sulfate esters and sulfamates of iodothyronines. Endocrinology. 117:1-7.

9. De Herder, W. W., M. P. Hazenberg, A. M. Pennock-Schröder, G. Hennemann, and T. J. Visser. 1986. Hydrolysis of iodothyronine glucuronides by obligately anaerobic bacteria isolated from human faecal flora. FEMS (Fed. Eur. Microbiol. Soc.) Microbiol. Lett. 35:249-253.

10. Flock, E. V., J. L. Bollman, and J. H. Grindlay. 1960. Conjugates of triiodothyronine and its metabolites. Endocrinology. 67:419429.

11. Flock, E. V., J. L. Bollman, and J. H. Grindlay. 1960. 3,3'Diiodothyronine, a metabolite of 3,5,3'-triiodothyronine. Proc. Mayo Clin. 35:75-81.
12. Flock, E. V., and J. L. Bollman. 1962. The effect of thiouracil on the metabolism of L-thyroxine. Biochem. J. 84:621-626.

13. Flock, E. V., J. L. Bollman, C. A. Owen, Jr., and P. E. Zollman. 1965. Conjugation of thyroid hormones and analogs by the Gunn rat. Endocrinology. 77:303-314.

14. Roche, J., R. Michel, J. Closon, and O. Michel. 1959. Sur la sulfoconjugaison hépatique de la 3,5,3'-triiodothyronine et la présence d'un ester sulfurique de cette hormone dans la bile et la plasma. Biochim. Biophys. Acta. 33:461-468.

15. Kaplan, M. M. 1986. Regulatory influences on iodothyronine deiodination in animal tissues. In Thyroid Hormone Metabolism. G. Hennemann, editor. Marcel Dekker, New York. 231-254.

16. Nimalasuriya, A., L. Y. Mizuno, C. A. Spencer, A. Marcus, and J. T. Nicoloff. 1984. Program of the 60th Annual Meeting of the American Thyroid Association, New York, NY. 57. (Abstr.)

17. Silva, J. E., M. B. Gordon, F. R. Crantz, J. L. Leonard, and P. R. Larsen. 1984. Qualitative and quantitative differences in the pathways of extrathyroidal triiodothyronine generation between euthyroid and hypothyroid rats. J. Clin. Invest. 73:898-907.

18. Roche, J., R. Michel, J. Closon, and O. Michel. 19.60. Sur le métabolisme du sulfoconjugué de la 3,5,3'-triiodothyronine chez le rat. Biochim. Biophys. Acta. 38:325-332.

19. Eelkman Rooda, S. J., E. Kaptein, M. A. C. Van Loon, and T. J. Visser. 1986. Sulfate conjugation of $T_{3}$ by rat hepatocytes as analysed by a $\mathrm{T}_{3}$ sulfate radioimmunoassay. Ann. Endocrinol. 47:24. (Abstr.)

20. Young, W. F., C. A. Gorman, and R. M. Weinshilboum. 1986. Triiodothyronine $\left(\mathrm{T}_{3}\right)$ : a substrate for two forms of human phenol sulfotransferase (PST). Program of the 61st Annual Meeting of the American Thyroid Association, Phoenix, AZ. 45. (Abstr.)

21. Visser, T. J., and E. P. Krenning. 1983. Deiodination of iodothyronines in human liver. Program of the 59th Annual Meeting of the American Thyroid Association, New Orleans, LA. 31. (Abstr.) 